\title{
Community and facility-based tuberculosis control: Programmatic comparison and experience from Nepal
}

\author{
Dev Joshi $^{\mathrm{a}, \mathrm{b}}$, Ashish Awasthi ${ }^{\mathrm{a}, \mathrm{c}, *}$, Anurag Saxena ${ }^{\mathrm{a}}$, Deepak Saxena ${ }^{\mathrm{a}}$, Dileep Mavalankar ${ }^{\mathrm{a}}$ \\ ${ }^{a}$ Indian Institute of Public Health, Gandhinagar, India \\ ${ }^{\mathrm{b}}$ District Health Office, Baitadi, Ministry of Health and Population, Nepal \\ ${ }^{\mathrm{c}}$ Public Health Foundation of India, Gurugram, India
}

\section{A R T I C L E I N F O}

\section{Keywords:}

CB DOTS

FB DOTS

Community

Implement,Program,TB

Treatment,Tuberculosis

\begin{abstract}
A B S T R A C T
Background: Successful treatment is an essential aspect of tuberculosis (TB) elimination and prevention against drug resistance. The loss to follow up, and treatment failure is the main causes of poor treatment outcome. To prevent these causes from hindering successful treatment of TB patient and increase adherence to treatment, Community Based Directly Observed Treatment Short course (CB DOTS) program are being promoted. This study aims to compare programmatic treatment outcome for all new TB cases registered in Community Based DOTS and Facility-Based DOTS (FB DOTS) program in districts of Nepal.

Methodology: Analysis of secondary data was carried out to document the outcome of TB patients registered in 2015-16 in terms of success, loss to follow up, treatment failure, and death for CB DOTS in eleven districts of Nepal using publicly available data. Each CB DOTS district was then matched with 11 FB DOTS district to compare the outcomes. The selection was based on pre-decided criteria like districts from similar geographies, population, and same ecology.

Finding: Districts in which community-based DOTS was implemented showed better median treatment success rate $(92.88 \%)$ than facility-based DOTS implemented districts $(89.84 \%)(\mathrm{p}=0.02)$. The median loss to follow up the rate of community-based DOTS implemented districts $(0.92 \%)$ was better than the median loss to follow uprate of facility-based DOTS implemented districts $(2.967 \%)(\mathrm{p}=0.02)$.

Conclusion: Compared to the Facility-Based DOTS, Community Based DOTS approach was found to be more effective in terms of treatment outcome and adherence to treatment. Community-based treatment is a patientcentered approach for tuberculosis treatment and is found to be more useful to achieve high treatment success rate in countries like Nepal that have rough terrain and limited connectivity to some regions.
\end{abstract}

\section{Introduction}

Tuberculosis is a critical health problem throughout the globe. Emphasizing the need for concrete efforts to eliminate Tuberculosis, one of the Sustainable Development Goal (SDG) aims at ending tuberculosis endemic by 2030, i.e., the SDGs and End TB Strategy of World Health Organization (WHO) share a common aim, to end the global TB epidemic. ${ }^{1,2}$ Targets set by the End TB Strategy include a $90 \%$ reduction in TB deaths and an $80 \%$ reduction in TB incidence by 2030 , compared with 2015.

WHO End TB Strategy, adopted by the World Health Assembly in May 2014, envisaged ending TB epidemic by minimizing TB related deaths, the incidence of $\mathrm{TB}$, and eliminating catastrophic costs. The strategy aims to reduce TB related deaths by $95 \%$, reduce new cases by 90\% between 2015 and 2035, and to ensure that no family is burdened with terrible costs due to TB. ${ }^{3}$ To achieve the goal of ending TB epidemic by 2030, WHO outlined three strategic pillars that are (a) integrated patient-centered care and prevention, (b) bold policies and supportive systems, and (c) intensified research and innovation. ${ }^{1-3}$

In 2016, 6.3 million new cases of tuberculosis were detected across the globe, and 1.67 million died due to tuberculosis. ${ }^{3,4}$ In 2016, the total disability-adjusted life years (DALY) loss due to tuberculosis was 40 million years, and more than $95 \%$ of this loss was from low and middle-income countries. ${ }^{3,4}$ On a bright side, from 2000 to 2016, an estimated 53 million lives were saved due to TB diagnosis and treatment. $^{3}$ In recent years, drug-resistant TB has emerged as one of the main crisis and threat to public health systems across the world. Globally, in 2016, about 6,00,000 new cases of TB were resistance to the most effective first-line drug Rifampicin, $82 \%$ of these cases were Multi-Drug Resistance Tuberculosis (MDR-TB). ${ }^{1}$ MDR-TB treatment

\footnotetext{
* Corresponding author. Public Health Foundation of India, Plot No. 47, Sector 44 Institutional Area, Gurugram, 122002. India.

E-mail address: ashish.awasthi@phfi.org (A. Awasthi).
} 
require expensive drugs including injectable, have severe side effects, and recommended regimen (called second-line treatment) must be taken for up to two years. ${ }^{3}$ The cure rate for MDR-TB is low, typically ranging from around $50 \%-70 \%$. In 2016 , worldwide $83 \%$ of drugsensitive TB cases were treated successfully, whereas, only $54 \%$ of MDR-TB patients and 30\% of Extensively Drug Resistance TB (XDR-TB) were successfully treated. ${ }^{3}$ Globally, countries are marching towards achieving Sustainable Development Goal (SDG) and End TB Strategy to eliminate tuberculosis.

In Nepal, current practice to treat tuberculosis is based on two distinct approaches. One is to treat TB patients according to DOTS strategy in clinics. In this approach, TB drug is administered to patients by a health worker at the DOTS clinic. This approach is called Facility Based Directly Observed Treatment Short course (FB DOTS). Another approach is a patient-centered approach to treat TB patient near the door of the patient and is referred to as Community Based Directly Observed Treatment Short course (CB DOTS). According to CB DOTS guideline of National Tuberculosis Control Program of the Government of Nepal, TB patients living at places which are at more than half an hour distance from DOTS centre; very old, pregnant and postpartum mother; and disabled people are treated in CB DOTS under the daily supervision of trained DOTS volunteer. As a result, about $40 \%$ of the TB patient is treated using CB DOTS approach and the remaining $60 \%$ are treated using FB DOTS approach in the districts where both the programs are implemented.

A successful treatment is an important aspect to eliminate TB and prevent drug-resistant cases. The loss to follow up from treatment, and treatment failure is the leading causes of the poor outcome. To prevent these causes from hindering successful treatment of TB patients and to boost adherence to the treatment regime, CB DOTS program is promoted by the government of Nepal. To the best of our knowledge, till date, the programmatic outcome of CB DOTS and FB DOTS in Nepal has not been studied. Research on outcomes of CB DOTS and FB DOTS in the context of other countries has given mixed results. In this regard, this study aims to determine and compare programmatic treatment outcome of CB DOTS and FB DOTS program implemented in Nepal.

\section{Methodology}

\subsection{Study design}

This is secondary data analysis of district-level data maintained by TB control program, Government of Nepal. Data is available through the webpage www.nepalntp.gov.np

\subsection{Study setting}

According to 2011 census, Nepal had 26.4 million population with $48 \%$ of them being male and $52 \%$ female. The eco-terrain of Nepal can be divided into Terai, Hill and Mountain region. 50.3\% of the total population live in Terai, $43 \%$ live in Hill, and 6.7\% live in Mountain region. ${ }^{5}$ For more than a decade, Nepal achieved $90 \%$ treatment success rate. To intensify tuberculosis treatment program, Government of Nepal started a pilot program of CB DOTS in 5 districts in 2013 which was later expanded to 21 districts in a phased manner.

\subsection{Definition}

Various definitions used in tuberculosis case registration and reporting applied in this study given in Table 1 are according to WHO's Guideline for treatment of drug-susceptible tuberculosis and patient care and Definitions and reporting framework for tuberculosis 2013 revision. ${ }^{6,7}$

\subsection{Data collection and sample size}

Latest data published by the National tuberculosis control program of Nepal for the financial year 2016-17 was collected. Of the 21 districts in which CB DOTS has been implemented, the data contained details for 11 districts (In 10 districts, CB DOTS program was implemented in the financial year 2016-17. Data for these 10 districts will be available at the end of Nepal's 2017-18 financial year, i.e., after mid-July 2018). All 11 districts for which CB DOTS program data was available were selected for this study. These districts are namely Dhankuta, Solukhaumbu, Chitawan, Dhading, Kaski, Navalparasi, Palpa, Rukum, Surkhet, Baitadi, and Kailali. Each CB DOTS program implemented district was matched with FB DOTS program implemented district one to one on the basis of similar development region, same ecological region, similar population and adjoining geography. Total 4745 patients registered in CB DOTS and 3339 patients registered in FB DOTS program implemented districts during 15 July 2015 to 14 July 2016 were assessed and district wise outcome in terms of treatment success, loss to follow up, treatment failure and death of all form of new TB patient registered in 2015-16 were analyzed and compared.

\subsection{Inclusion criteria}

9057 total TB patient are registered in financial year 2015-16. Among them 3703 were on FB DOTS and 5354 are on CB DOTS

Table 1

Definition used in study.

\begin{tabular}{|c|c|}
\hline Terms used & Definitions \\
\hline CB DOTS & DOTS delivered in the community that is close to the patient's home or workplace by community trained volunteers. \\
\hline FB DOTS & DOTS delivered at a health centre, clinic or hospital by health workers. \\
\hline New TB patients & Have never been treated for TB or have taken anti-TB drugs for less than 1 month. \\
\hline $\begin{array}{l}\text { Previously treated patients (Re treatment } \\
\text { patient) }\end{array}$ & $\begin{array}{l}\text { Have received } 1 \text { month or more of anti-TB drugs in the past. They are further classified by the outcome of their most recent course of } \\
\text { treatment as Relapse, Treatment after failure, Treatment after loss to follow up, Other previously treated and Previous TB treatment } \\
\text { history unknown. }\end{array}$ \\
\hline Cured & $\begin{array}{l}\text { A pulmonary TB patient with bacteriologically confirmed TB at the beginning of treatment who was smear- or culture-negative in the } \\
\text { last month of treatment and on at least one previous occasion. }\end{array}$ \\
\hline Treatment completed & $\begin{array}{l}\text { A TB patient who completed treatment without evidence of failure but with no record to show that sputum smear or culture results } \\
\text { in the last month of treatment and on at least one previous occasion were negative, either because tests were not done or because } \\
\text { results are unavailable. }\end{array}$ \\
\hline Treatment failed & A TB patient whose sputum smear or culture is positive at month 5 or later during treatment. \\
\hline Died & $\begin{array}{l}\text { A TB patient who dies for any reason during the course of treatment. } \\
\text { Treatment success: The sum of cured and treatment completed. }\end{array}$ \\
\hline Lost to follow-up: & A TB patient whose treatment was interrupted for 2 consecutive months or more. \\
\hline Not evaluated & $\begin{array}{l}\text { A TB patient for whom no treatment outcome is assigned. This includes cases "transferred out" to another treatment unit as well as } \\
\text { cases for whom the treatment outcome is unknown to the reporting unit. }\end{array}$ \\
\hline
\end{tabular}

WHO. Definitions and reporting framework for tuberculosis-2013 revision. 
Table 2

FB DOTS and CB DOTS program implemented districts, new TB patient (all form) registered and their treatment outcome.

\begin{tabular}{|c|c|c|c|c|c|c|c|c|}
\hline & $\begin{array}{l}\text { Program Implemented } \\
\text { Districts }\end{array}$ & $\begin{array}{l}\text { Registered New TB cases } \\
\text { (All form) }\end{array}$ & $\begin{array}{l}\text { Successfully treated, } \mathrm{n} \\
(\%)\end{array}$ & Failure, n (\%) & Died, n (\%) & $\begin{array}{l}\text { Loss to follow up, n } \\
(\%)\end{array}$ & $\begin{array}{l}\text { Not evaluated, } \mathrm{n} \\
(\%)\end{array}$ & Total \\
\hline \multirow[t]{12}{*}{ FB DOTS } & Bhojpur & 55 & 48 (87.27) & $0(0.00)$ & $2(3.64)$ & $3(5.45)$ & $2(3.64)$ & 55 \\
\hline & Sankhuvasava & 84 & $80(95.24)$ & $2(2.38)$ & 1 (1.19) & $0(.00)$ & 1 (1.19) & 84 \\
\hline & Makwanpur & 690 & $619(89.71)$ & $7(1.01)$ & $11(1.59)$ & $40(5.80)$ & 13 (1.88) & 690 \\
\hline & Sindhuli & 281 & $259(92.17)$ & $5(1.78)$ & $3(1.07)$ & $9(3.20)$ & $5(1.78)$ & 281 \\
\hline & Baglung & 132 & $119(90.15)$ & $3(2.27)$ & $4(3.03)$ & $2(1.52)$ & $4(3.03)$ & 132 \\
\hline & Gulmi & 272 & $240(88.24)$ & $3(1.10)$ & $20(7.35)$ & $3(1.10)$ & $6(2.21)$ & 272 \\
\hline & Kapil & 575 & $528(91.83)$ & $10(1.74)$ & $19(3.30)$ & $17(2.96)$ & $1(.17)$ & 575 \\
\hline & Dailekh & 187 & $168(89.84)$ & $0(.00)$ & $6(3.21)$ & $6(3.21)$ & 7 (3.74) & 187 \\
\hline & Rolpa & 237 & $219(92.41)$ & $1(.42)$ & $12(5.06)$ & $5(2.11)$ & $0(.00)$ & 237 \\
\hline & Doti & 135 & $110(81.48)$ & $2(1.48)$ & 15 (11.11) & $8(5.93)$ & $0(.00)$ & 135 \\
\hline & Kanchanpur & 691 & $610(88.28)$ & $6(.87)$ & $34(4.92)$ & 13 (1.88) & $28(4.05)$ & 691 \\
\hline & Total & 3339 & $3000(89.85)$ & $39(1.17)$ & $127(3.80)$ & $106(3.17)$ & $67(2.01)$ & 3339 \\
\hline \multirow[t]{12}{*}{ CB DOTS } & Dhankuta & 86 & $80(93.02)$ & $3(3.49)$ & $2(2.33)$ & $0(.00)$ & $1(1.16)$ & 86 \\
\hline & Solukhumbu & 17 & $17(100.00)$ & $0(.00)$ & $0(.00)$ & $0(.00)$ & $0(.00)$ & 17 \\
\hline & Chitwan & 838 & $766(91.41)$ & $7(.84)$ & $25(2.98)$ & 14 (1.67) & $26(3.10)$ & 838 \\
\hline & Dhading & 247 & 243 (98.38) & $0(.00)$ & $4(1.62)$ & $0(.00)$ & $0(.00)$ & 247 \\
\hline & Kaski & 435 & $402(92.41)$ & $3(.69)$ & $22(5.06)$ & $4(.92)$ & $4(.92)$ & 435 \\
\hline & Nawalparasi & 776 & $714(92.01)$ & $6(.77)$ & $26(3.35)$ & $21(2.71)$ & $9(1.16)$ & 776 \\
\hline & Palpa & 323 & $300(92.88)$ & $3(.93)$ & $14(4.33)$ & $1(.31)$ & 5 (1.55) & 323 \\
\hline & Rukum & 217 & $212(97.70)$ & $2(.92)$ & $3(1.38)$ & $0(.00)$ & $0(.00)$ & 217 \\
\hline & Surkhet & 614 & $582(94.79)$ & $2(.33)$ & $15(2.44)$ & $8(1.30)$ & $7(1.14)$ & 614 \\
\hline & Baitadi & 198 & $178(89.90)$ & $2(1.01)$ & $14(7.07)$ & $3(1.52)$ & $1(.51)$ & 198 \\
\hline & Kailali & 994 & 871 (87.63) & $6(.60)$ & $43(4.33)$ & 47 (4.73) & $27(2.72)$ & 994 \\
\hline & Total & 4745 & 4365(91.99) & $34(0.72)$ & $168(3.54)$ & $98(2.07)$ & $80(1.69)$ & 4745 \\
\hline
\end{tabular}

program implemented districts. 3339 patients from FB DOTS and 4745 patients from FB DOTS program implemented districts are included for analysis on basis of registration category "new TB patients" (all forms). Remaining "retreatment" and "other" registration category patient are excluded for the present analysis.

\subsection{Data management}

Normality of data was checked by the Shapiro-Wilk test. As data were not normally distributed, Wilcoxon rank sum test was used to compare the effect of CB DOTS and FB DOTS program. All the hypotheses were two-sided with a $5 \%$ level of significance. All calculations were performed in $\mathrm{R}$ version 3.4.1using "Rcmdr" package. ${ }^{8}$

\section{Results}

Out of 3339 all form of (Pulmonary Bacteriologically Conformed, Pulmonary clinically diagnosed and Extra pulmonary) new TB patients registered in eleven FB DOTS implemented districts during July 15, 2016 to 14 July $2017 ; 89.85 \%(n=3000)$ were successfully treated, $1.17 \%(\mathrm{n}=39)$ were failure, $3.8 \%(\mathrm{n}=127)$ died, $3.17 \%(\mathrm{n}=106)$ were defaulter, and $2.01 \%(n=67)$ were not evaluated [Table 2]. In eleven CB DOTS implemented districts, 4745 all form of (Pulmonary Bacteriologically conformed, Pulmonary clinically diagnosed and Extra pulmonary) new TB patients were registered in the same period. Among them, $91.99 \%(n=4365)$ were successfully treated, $0.72 \%(n=34)$ were treatment failure, 3.54\% $(n=168)$ died, $2.07 \%(n=98)$ were defaulter, and $1.69 \%(n=80)$ were not evaluated [ Fig. 1].

Table 3 shows that CB DOTS implemented districts had better median treatment success rate $(92.88 \%)$ than FB DOTS implemented districts $(89.84 \%), \mathrm{p}=0.02$. Similarly, lost to follow-up was statistically significant $(\mathrm{p}=0.02)$ in CB DOTS implemented districts $(0.92 \%)$ in comparison of FB DOTS implemented districts (2.96\%), On the other hand, median treatment failure rate and median death rate of CB DOTS program implemented districts was $0.77 \%$ and $2.98 \%$ respectively which is better in comparison to FB DOTS implemented districts $(1.10 \%$ and $3.30 \%$ respectively) but not significant $\mathrm{p}=0.17$ and 0.56 respectively [Fig. 2, Table 3]. Appendix 1 shows gender wise comparison of both treatment modalities in various districts of Neapl.

\section{Discussion}

Our findings shows that despite only $40 \%$ patients being treated through CB DOTS approach, better treatment success rate $(3.04 \%$ higher) and better loss to follow-up rate (2.03\% lower) was observed in CB DOTS implemented districts than FB DOTS districts. This may be due to better access to treatment by the patients (in terms of treatment is near to their home, and flexibility of time to take DOTS than health facility). In line with the findings of this research work, it has been reported that in comparison to FB DOTS, CB DOTS not only provide better treatment outcomes, but it also helps in reducing the cost associated with tuberculosis treatment by $40-50 \%{ }^{9}$

There is some research work on the effectiveness of CB DOTS approach, but till date the findings are inconsistent. In a systemic review, Volmink $J$ and Garner P. reported no significant difference in clinical outcomes (treatment success) between DOTS at a clinic versus DOTS by a family member or community health worker. ${ }^{10}$ Another systematic review and meta-analysis by Zhang et al. concluded that CB DOTS promote successful treatment (pooled RR 95\%, CI 1.02-1.19), and reduce mortality (pooled RR 95\%, CI 0.26-0.72) and transfer out (pooled RR 95\%, CI 0.23-0.61), but had no effect on curative treatment, treatment default, and treatment failure as compared to FB DOTS. ${ }^{11}$ Systematic review and meta-analysis by Wright et al. found that $\mathrm{CB}$ DOTS gives better treatment success than FB DOTS (OR of 1.54, 95\%, CI 1.01-2.36, P 0.046), however, no statistically significant difference was reported between the two DOTS modalities for loss to follow-up (pooled OR $0.86,95 \%$, CI 0.48 to 1.55 , P 0.62 ). ${ }^{12}$

Similar to the findings of this study, Tripathy et al. on comparing the treatment success rate in Banglore (India) found that CB DOTS has $93 \%$ success rate and that of those undergoing FB DOT has $75 \%$ success rate (RR 1.23, 95\%CI 1.19-1.28). ${ }^{13}$ A case-control study in Uganda before and after execution of CB DOTS program by Adatu et al. demonstrated that following the implementation of CB-DOTS, treatment success among new smear-positive pulmonary TB cases increased from $56 \%$ to 


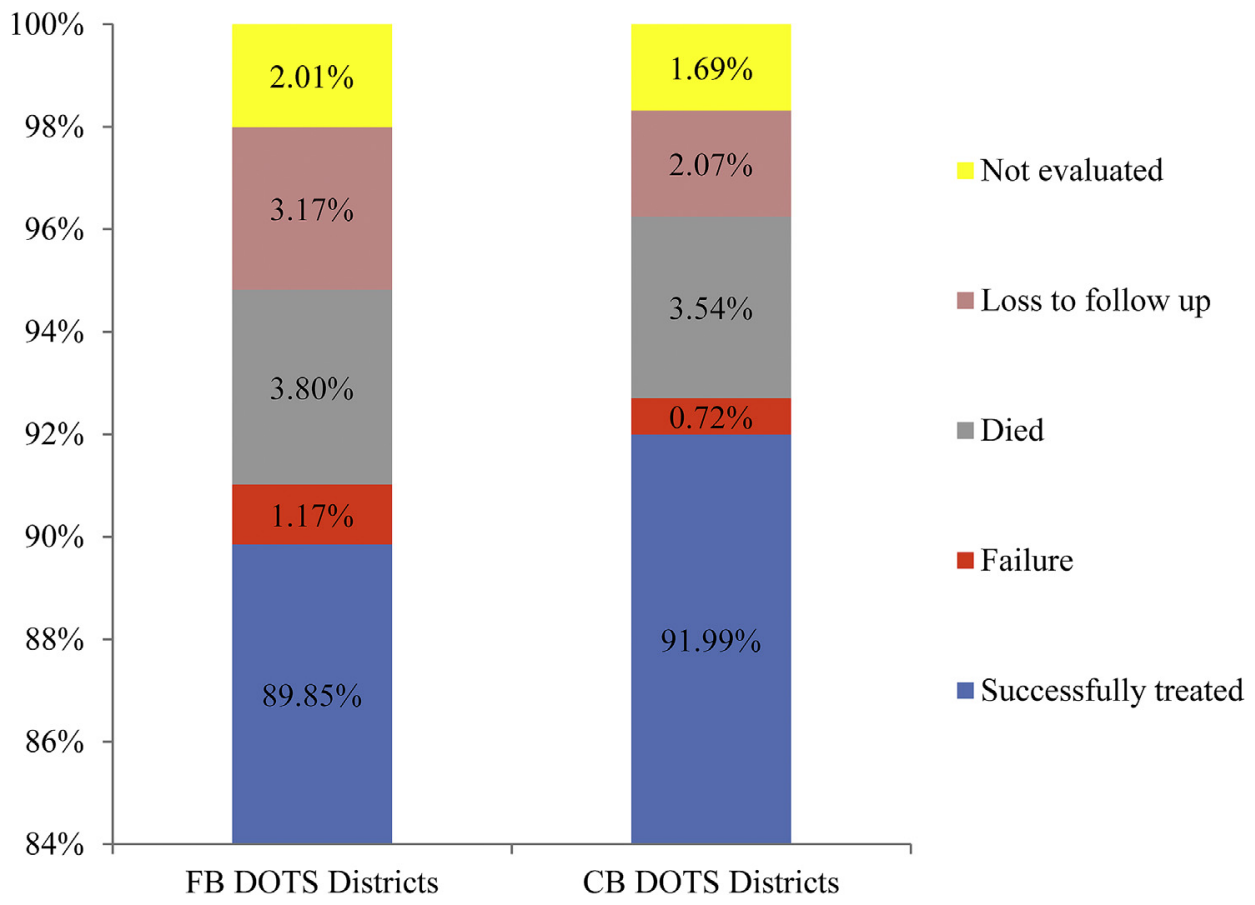

Fig. 1. Total new TB patient (all form) registered in FB DOTS $(n=3339)$ and CB DOTS $(n=4745)$ program implemented districts and their outcome.

Table 3

Comparison of treatment outcome of FB DOTS and CB DOTS program implemented districts.

\begin{tabular}{|c|c|c|c|c|c|c|}
\hline Treatment Outcome & Implemented Program & Number of Districts & Median & $25^{\text {th }}$ percentile & $75^{\text {th }}$ percentile & $\mathrm{p}$ value \\
\hline \multirow[t]{2}{*}{ Treatment Success Rate (TSR) } & FB_DOTS & 11 & 89.84 & 88.26 & 92.00 & 0.02 \\
\hline & CB_DOTS & 11 & 92.88 & 91.71 & 96.24 & \\
\hline \multirow[t]{2}{*}{ Loss to Follow up Rate (LFR) } & FB_DOTS & 11 & 2.96 & 1.70 & 4.33 & 0.02 \\
\hline & CB_DOTS & 11 & 0.92 & 0.00 & 1.59 & \\
\hline \multirow[t]{2}{*}{ Failure Rate (FR) } & FB_DOTS & 11 & 1.10 & 0.65 & 1.76 & 0.17 \\
\hline & CB_DOTS & 11 & 0.77 & 0.46 & 0.93 & \\
\hline \multirow[t]{2}{*}{ Death Rate (DR) } & FB_DOTS & 11 & 3.30 & 2.31 & 4.99 & 0.56 \\
\hline & CB_DOTS & 11 & 2.98 & 1.97 & 4.33 & \\
\hline
\end{tabular}

Median TSR

$\square$ TSR

\section{Median LFR, FR \& DR}

$\square$ FB_DOTS $\square$ CB_DOTS

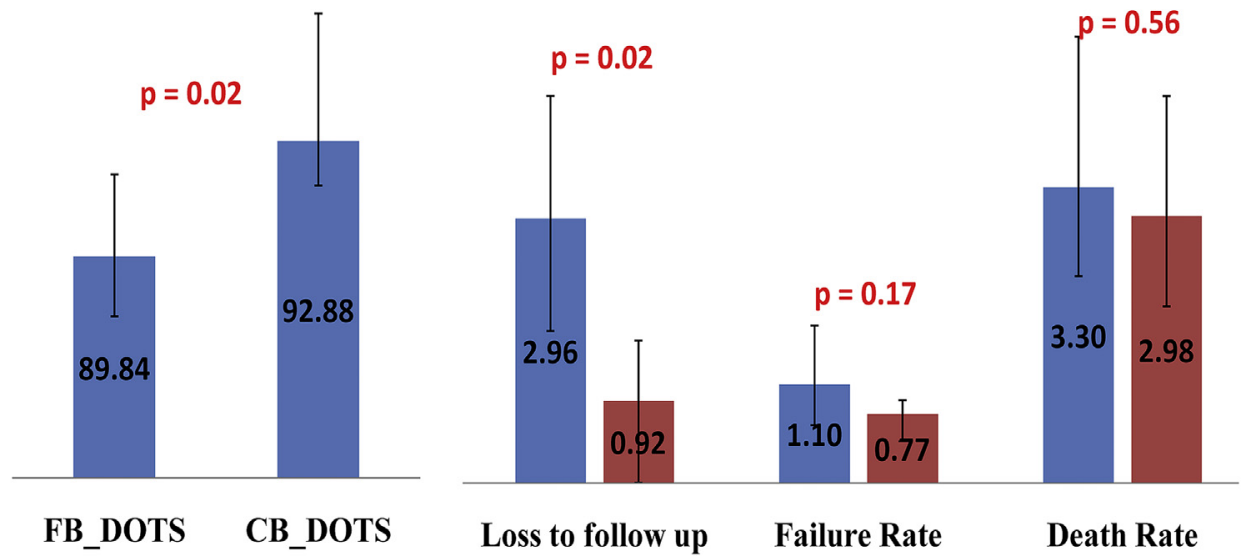

Fig. 2. Median treatment outcome of TB patient registered in FBDOTS and CB DOTS program implemented districts and their statistical relation (Error bars represents inter-quartile range). 
74\% (RR 1.3, 95\%CI 1.2-1.5, P 0.001), loss to follow up decreased from $23 \%$ to $1 \%$ (RR $16.5,95 \% \mathrm{CI} 6.144 .7, \mathrm{P} 0.001$ ), and there was no significant difference in the proportion of deaths. ${ }^{14}$

\subsection{Limitations}

This study is based on secondary data, hence, the accuracy of results is dependent on the quality of the process that was used for collecting the data. Presence of any bias in the collected data may have a negative impact on the robustness of conclusions made in this study. However, there is no basis to doubt the quality of data. As comparison unit in the present study was a district, only 11 CB DOTS implemented districts were eligible for treatment outcome analysis, thus limiting sample size for the study.

As the unit of analysis for this study was a district, hence, some essential characteristics such as age, sex, geographical situation, and socio-economic factors were not analyzed. There is a possibility that it may limit the generalizability of the findings of this study.

\section{Conclusion}

Based on the results of this study, it can be concluded that in the context of Nepal, CB DOTS approach was found to be effective in terms of treatment outcome. Average treatment success rate was higher and average loss to follow-up was lower in CB DOTS program implemented districts than FB DOTS implemented districts. Treatment failure and death rates were also lower in CB DOTS program implemented districts but were not statistically significant. The objective of CB DOTS program implementation in Nepal is not only limited to daily administration of TB drugs closer to the home of ТВ patients, but it also involves the community in the timely identification of TB patients and reduces stigma related to tuberculosis in the community. This also adds synergic in the efforts for early identification and prompt treatment of hidden TB patient in a community. Hence, in the context of geographically complex countries like Nepal, being a patient-centered approach; implementation of CB DOTS program may become a mean to achieve the SDG goal of overall TB elimination.

\section{Conflicts of interest}

All authors declare they have no conflict of interest. Funding agencies have no role in writing or in submission of the manuscript.

\section{Acknowledgment}

Dev Joshi acknowledges assistance and support from Government of Nepal, Ministry of Health, National Tuberculosis Control Program of Nepal, Mr. Pusp Raj Joshi (Statistics officer, Government of Nepal) and Mr. Manoj Prashad Ojha (TB Leprosy Officer, Government of Nepal). Ashish Awasthi received funding from Department of Science and Technology, Government of India, New Delhi, through INSPIRE Faculty Award Scheme.

Appendix 1. FB DOTS and CB DOTS program implemented districts, sex wise new TB patient (all form) registered and their treatment outcome

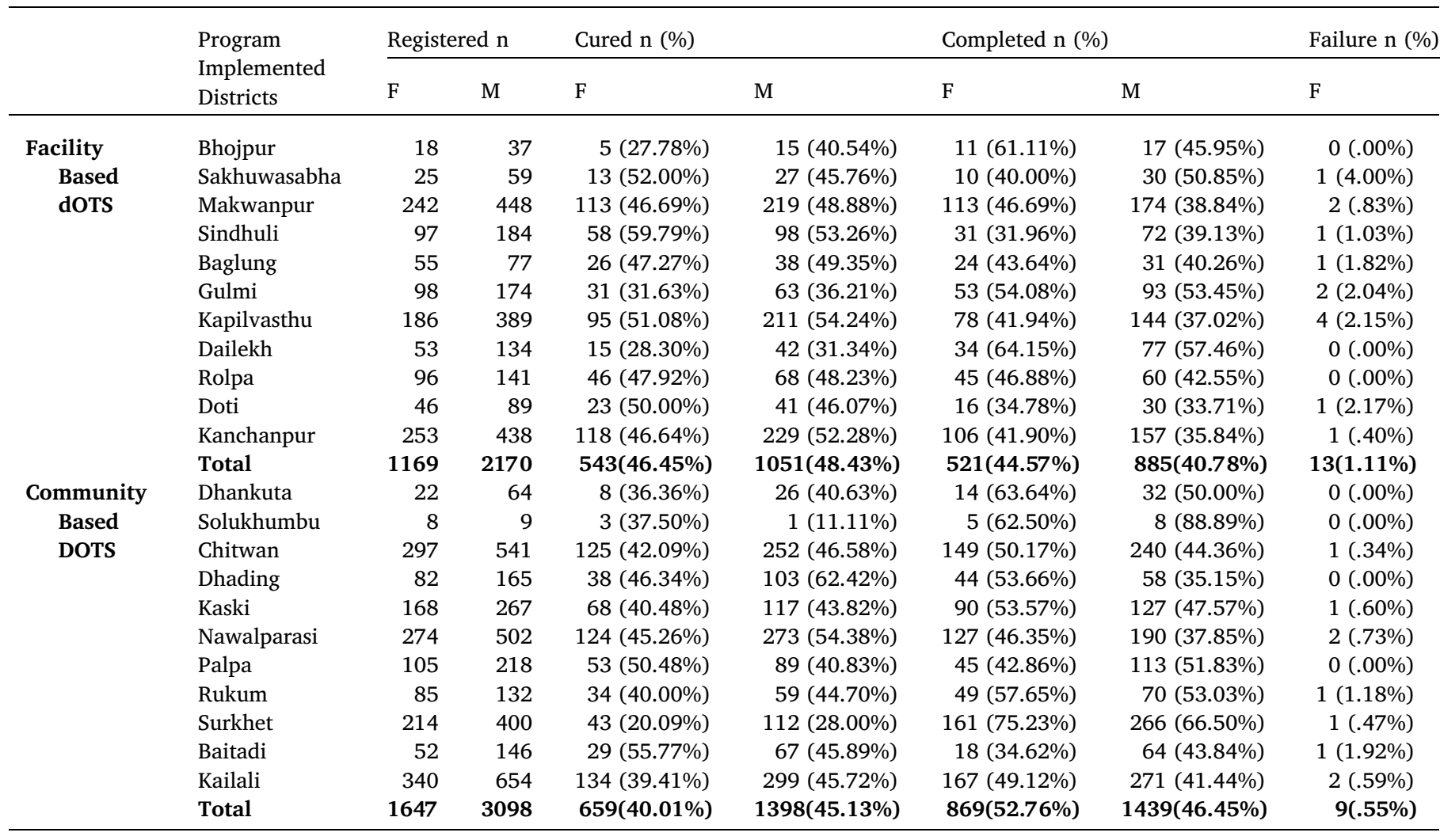

\begin{tabular}{|c|c|c|c|c|c|c|c|c|}
\hline $\begin{array}{l}\text { Failure n (\%) } \\
\mathrm{M}\end{array}$ & \multicolumn{2}{|l|}{ Died n (\%) } & \multicolumn{2}{|c|}{ Lost to Follow-up n (\%) } & \multicolumn{2}{|c|}{ Not Evaluated n (\%) } & \multicolumn{2}{|c|}{ Total n } \\
\hline $0(.00 \%)$ & $0(.00 \%)$ & $2(5.41 \%)$ & $1(5.56 \%)$ & $2(5.41 \%)$ & $1(5.56 \%)$ & $1(2.70 \%)$ & 18 & 37 \\
\hline $1(1.69 \%)$ & $0(.00 \%)$ & $1(1.69 \%)$ & $0(.00 \%)$ & $0(.00 \%)$ & $1(4.00 \%)$ & $0(.00 \%)$ & 25 & 59 \\
\hline
\end{tabular}




\begin{tabular}{|c|c|c|c|c|c|c|c|c|c|}
\hline Facility & $5(1.12 \%)$ & $2(.83 \%)$ & $9(2.01 \%)$ & $8(3.31 \%)$ & $32(7.14 \%)$ & $4(1.65 \%)$ & $9(2.01 \%)$ & 242 & 448 \\
\hline Based & $4(2.17 \%)$ & $2(2.06 \%)$ & $1(.54 \%)$ & $2(2.06 \%)$ & $7(3.80 \%)$ & $3(3.09 \%)$ & $2(1.09 \%)$ & 97 & 184 \\
\hline \multirow[t]{8}{*}{ dOTS } & $2(2.60 \%)$ & $1(1.82 \%)$ & $3(3.90 \%)$ & $2(3.64 \%)$ & $0(.00 \%)$ & $1(1.82 \%)$ & $3(3.90 \%)$ & 55 & 77 \\
\hline & $1(.57 \%)$ & 7 (7.14\%) & $13(7.47 \%)$ & $1(1.02 \%)$ & $2(1.15 \%)$ & $4(4.08 \%)$ & $2(1.15 \%)$ & 98 & 174 \\
\hline & $6(1.54 \%)$ & $4(2.15 \%)$ & $15(3.86 \%)$ & $5(2.69 \%)$ & $12(3.08 \%)$ & $0(.00 \%)$ & $1(.26 \%)$ & 186 & 389 \\
\hline & $0(.00 \%)$ & $2(3.77 \%)$ & $4(2.99 \%)$ & $0(.00 \%)$ & $6(4.48 \%)$ & $2(3.77 \%)$ & $5(3.73 \%)$ & 53 & 134 \\
\hline & $1(.71 \%)$ & $5(5.21 \%)$ & $7(4.96 \%)$ & $0(.00 \%)$ & $5(3.55 \%)$ & $0(.00 \%)$ & $0(.00 \%)$ & 96 & 141 \\
\hline & $1(1.12 \%)$ & $4(8.70 \%)$ & $11(12.36 \%)$ & $2(4.35 \%)$ & $6(6.74 \%)$ & $0(.00 \%)$ & $0(.00 \%)$ & 46 & 89 \\
\hline & $5(1.14 \%)$ & $8(3.16 \%)$ & $26(5.94 \%)$ & $5(1.98 \%)$ & $8(1.83 \%)$ & $15(5.93 \%)$ & $13(2.97 \%)$ & 253 & 438 \\
\hline & $26(1.20 \%)$ & $35(2.99 \%)$ & $92(4.24 \%)$ & $26(2.22 \%)$ & $80(3.69 \%)$ & $31(2.65 \%)$ & $36(1.66 \%)$ & 1169 & 2170 \\
\hline Community & $3(4.69 \%)$ & $0(.00 \%)$ & $2(3.13 \%)$ & $0(.00 \%)$ & $0(.00 \%)$ & $0(.00 \%)$ & $1(1.56 \%)$ & 22 & 64 \\
\hline Based & $0(.00 \%)$ & $0(.00 \%)$ & $0(.00 \%)$ & $0(.00 \%)$ & $0(.00 \%)$ & $0(.00 \%)$ & $0(.00 \%)$ & 8 & 9 \\
\hline \multirow[t]{10}{*}{ DOTS } & $6(1.11 \%)$ & $7(2.36 \%)$ & $18(3.33 \%)$ & $6(2.02 \%)$ & $8(1.48 \%)$ & $9(3.03 \%)$ & $17(3.14 \%)$ & 297 & 541 \\
\hline & $0(.00 \%)$ & $0(.00 \%)$ & $4(2.42 \%)$ & $0(.00 \%)$ & $0(.00 \%)$ & $0(.00 \%)$ & $0(.00 \%)$ & 82 & 165 \\
\hline & $2(.75 \%)$ & $7(4.17 \%)$ & $15(5.62 \%)$ & $0(.00 \%)$ & $4(1.50 \%)$ & $2(1.19 \%)$ & $2(.75 \%)$ & 168 & 267 \\
\hline & $4(.80 \%)$ & $8(2.92 \%)$ & $18(3.59 \%)$ & $7(2.55 \%)$ & $14(2.79 \%)$ & $6(2.19 \%)$ & $3(.60 \%)$ & 274 & 502 \\
\hline & $3(1.38 \%)$ & $6(5.71 \%)$ & $8(3.67 \%)$ & $1(.95 \%)$ & $0(.00 \%)$ & $0(.00 \%)$ & $5(2.29 \%)$ & 105 & 218 \\
\hline & $1(.76 \%)$ & $1(1.18 \%)$ & $2(1.52 \%)$ & $0(.00 \%)$ & $0(.00 \%)$ & $0(.00 \%)$ & $0(.00 \%)$ & 85 & 132 \\
\hline & $1(.25 \%)$ & $5(2.34 \%)$ & $10(2.50 \%)$ & $2(.93 \%)$ & $6(1.50 \%)$ & $2(.93 \%)$ & $5(1.25 \%)$ & 214 & 400 \\
\hline & $1(.68 \%)$ & $3(5.77 \%)$ & $11(7.53 \%)$ & $1(1.92 \%)$ & $2(1.37 \%)$ & $0(.00 \%)$ & $1(.68 \%)$ & 52 & 146 \\
\hline & $4(.61 \%)$ & $19(5.59 \%)$ & $24(3.67 \%)$ & $10(2.94 \%)$ & 37 (5.66\%) & $8(2.35 \%)$ & $19(2.91 \%)$ & 340 & 654 \\
\hline & $25(.81 \%)$ & $56(3.40 \%)$ & $112(3.62 \%)$ & $27(1.64 \%)$ & $71(2.29 \%)$ & $27(1.64 \%)$ & $53(1.71 \%)$ & 1647 & 3098 \\
\hline
\end{tabular}

\section{References}

1. WHO. Gear up to End TB: Introducing the End TB Strategy. World Health Organization; 2015.

2. Transforming UN. Our World: SDG Goals and Targets. United Nations; 2017.

3. Global WHO. Tuberculosis Report 2017. World Health Organization; 2018.

4. Naghavi M, Abajobir AA, Abbafati C, et al. Global, regional, and national age-sex specific mortality for 264 causes of death, 1980-2016: a systematic analysis for the Global Burden of Disease Study 2016. Lancet. 2017;390(10100):1151-1210.

5. WHO. WHO Country Cooperation Strategy 2013-2017: Nepal. World Health Organization and Government of Nepal; 2013.

6. WHO. Guidelines for the Treatment of Drug-susceptible Tuberculosis and Patient Care. World Health Organization; 2017.

7. WHO. Definitions and Reporting Framework for Tuberculosis-2013 Revision. World Health Organization; 2013.

8. R Core Team. R: a Language and Environment for Statistical Computing. Vienna, Austria: R Foundation for Statistical Computing; 2018https://www.R-project.org.

9. Newell JN, Baral SC, Pande SB, Bam DS, Malla P. Family-member DOTS and community DOTS for tuberculosis control in Nepal: cluster-randomised controlled trial. Lancet. 2006;367(9514):903-909.

10. Volmink J, Garner P. Directly observed therapy for treating tuberculosis. Cochrane Database Syst Rev. 2007;4.

11. Zhang H, Ehiri J, Yang H, Tang S, Li Y. Impact of community-based DOT on tuberculosis treatment outcomes: a systematic review and meta-analysis. PLoS One. 2016;11(2):e0147744.

12. Wright CM, Westerkamp L, Korver S, Dobler CC. Community-based directly observed therapy (DOT) versus clinic DOT for tuberculosis: a systematic review and metaanalysis of comparative effectiveness. BMC Infect Dis. 2015;15(1):210.

13. Tripathy S, Kumar P, Sagili K, Enarson D. Effectiveness of a community-based observation of anti-tuberculosis treatment in Bangalore City, India, 2010-2011. Public Health Action. 2013;3(3):230-234.

14. Adatu F, Odeke R, Mugenyi M, et al. Implementation of the DOTS strategy for tuberculosis control in rural Kiboga District, Uganda, offering patients the option of treatment supervision in the community, 1998-1999. Int J Tubercul Lung Dis. 2003;7(9):S63-S71. 